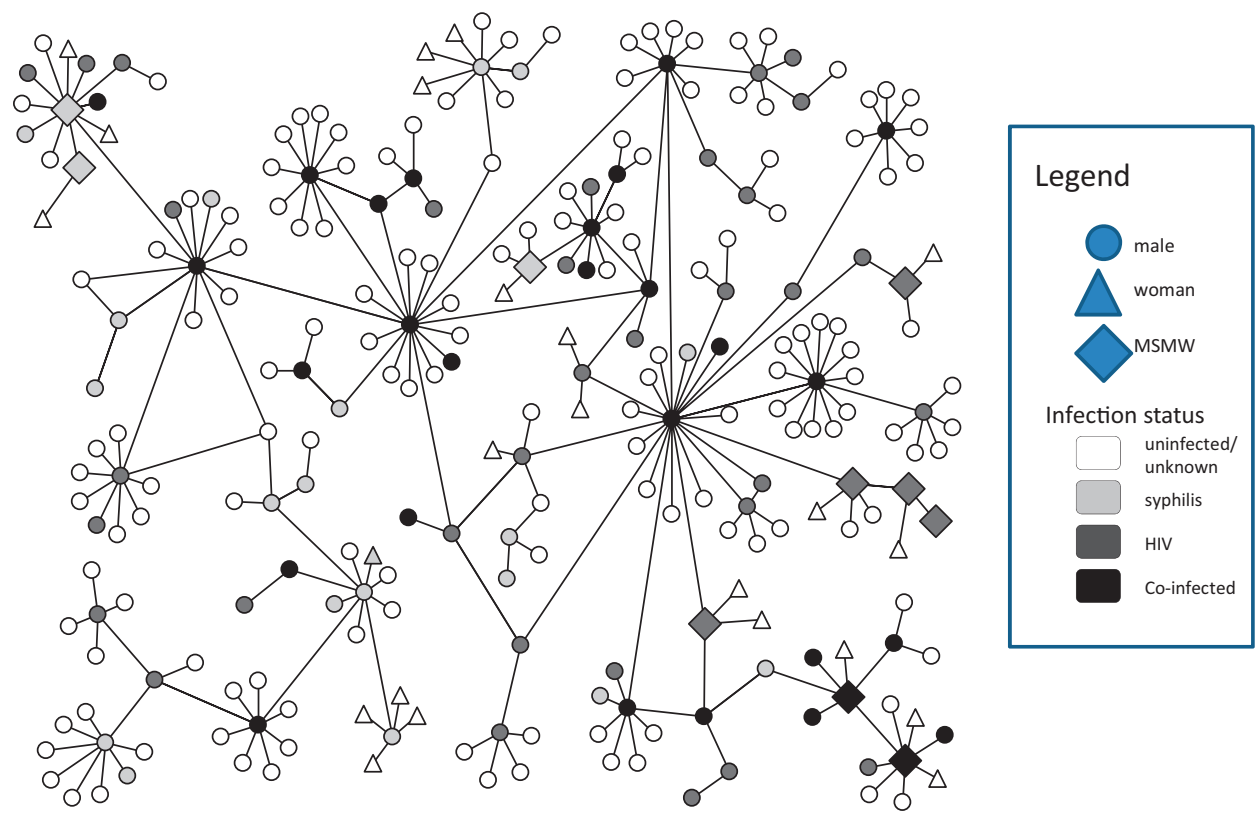

Abstract P1-S5.39 Figure 1 Infection Status.

$18 \%$ to $13 \%$ for ages $21-25,26-30$, and $31-35$ respectively, whereas women in each age group were equally distributed between $16 \%$ and $18 \%$. Women, MSW, and MSM, accounted for $31 \%, 32 \%$ and $30 \%$ respectively of cases; $7 \%$ were bisexual men. Though most heterosexuals had only syphilis, $16 \%$ were HIV + and $38 \%$ of them were coinfected. Among 196 bisexual and MSM, 73\% were HIV+; of these, half were coinfected. On the basis of timing of HIV and syphilis diagnoses and syphilis stage, an estimated 33\% of HIV+ men may have serosorted. Unlike other MSM populations, these cases did not use methamphetamine; $35 \%$ reported marijuana use. Crack cocaine use was reported for 16\% of MSW and 33\% of women. A total of 2099 individuals (cases, uninfected contacts, and anonymous partners) made up the network divided into 293 components. The largest component of 261 people (Abstract P1S5.39 figure 1) was predominantly MSM including 10 of the 36 MSMW. None of MSMWs' female partners had other partners, suggesting that onward transmission did not occur. Heterosexuals, engaging in transactional sex, comprised the second largest component involving at least 135 individuals; all cases were syphilisinfected.

Conclusions Contemporaneous syphilis and HIV epidemics persist among MSM; neither serosorting nor methamphetamine use fuels spread. Heterosexuals experienced a syphilis outbreak driven in part by transactional sex and crack cocaine use. Bisexual men did not bridge the populations. Frequent dual screening among MSM is critical to impede further transmission of both STIs.

\section{P1-S5.40 SEX CELLS: A PILOT STUDY INVESTIGATING CELL PHONE- BASED SEXUAL NETWORKS AMONG MEN WHO HAVE SEX WITH MEN IN SOUTH INDIA}

doi:10.1136/sextrans-2011-050108.218

${ }^{1} \mathrm{~L}$ H Thompson, ${ }^{1} \mathrm{~S}$ Shaw, ${ }^{2} \mathrm{~K}$ Deering, ${ }^{3} \mathrm{~S}$ Reza-Paul, ${ }^{1} \mathrm{R}$ Lorway. ${ }^{1}$ University of Manitoba, Winnipeg, Canada; ${ }^{2} B C$ Centre for Excellence in HIVIAIDS, Canada; ${ }^{3}$ Ashodaya-Disha, India

Background A high HIV prevalence (19-32\%) has been reported among men who have sex with men (MSM) in South India. Indeed, sexual networks play a central role in the spread of HIV in these communities but have rarely been studied because of intense social stigma and methodological and ethical challenges. Although cell phones are commonly used among MSM to contact sexual partners in India, few studies have explored the formation of such sexual networks. This study sought to understand the structure, context and evolution of cell phone-based sexual networks of MSM in three South Indian cities.

Methods Sampling frames in the three cities were established using MSM contacts stored in the cell phones of community-based researchers (CBRs). Study participant "seeds" were randomly selected from these social networks. Seeds were asked to recruit their sexual partners, who completed surveys about their sexual practices with regular partners and 7-day partners. Network diagrams were constructed using non-nominal codes linking study participants.

Results Cell phone contacts represent a useful resource for constructing social networks. Preliminary results indicate the diversity of sexual networks and sexual practices within these networks.

Conclusions New community-based methods of exploring sexual networks were assessed, and sexual practices, partner concurrency, and risk behaviours were explored. This information can be used to tailor more specific services for MSM in these communities. As this methodology sampled from social networks, more hidden "individuals who do not access health services were included in the study."

\section{P1-S5.41 OUANTIFYING THE CONTRIBUTION OF RE-INFECTION WITHIN PARTNERSHIPS TO PERSISTENT SPREAD OF CHLAMYDIA}

doi:10.1136/sextrans-2011-050108.219

${ }^{1} \mathrm{M}$ Kretzschmar, ${ }^{2} \mathrm{~B}$ Schmid, ${ }^{3} \mathrm{~N}$ Low, ${ }^{3} \mathrm{~J}$ Heijne. ${ }^{1}$ UMCU, Utrecht, Netherlands; ${ }^{2}$ RIVM, Netherlands; ${ }^{3}$ University of Bern, Switzerland

Background Many studies show that people testing positive and treated for genital chlamydia infection are at high risk of a repeat infection in the first year after treatment. Repeat infection can come from treatment failure, a new partner, or from within an existing partnership if the partner was not treated. Partnerships can therefore form a reservoir of chlamydia infections that might affect the effectiveness of population screening programs. It is not known how 
much reinfection within partnerships contributes to the persistent spread of chlamydia in heterosexual populations.

Methods We derive an expression for the basic reproduction number of an SIS infection in a population with long term monogamous partnerships. The basic reproduction number contains an explicit term quantifying the contribution of re-infection within partnerships to the overall reproduction number. The derivation is then extended to include partner notification and treatment. Finally, the model is extended to include two types of partnerships with differing average duration.

Results For small recovery rates and low transmission probabilities reinfection plays a minor role in sustaining chlamydia transmission. However, there is an optimal combination of duration of infection and transmission probability for which reinfection contributes substantially to keeping chlamydia endemic in a population. We discuss the functional dependency of the basic reproduction number on these parameters. Using a more complex model numerical scenarios were simulated showing that partner notification prevents a large proportion of re-infections.

Conclusions The effect of screening depends, in part, on whether or not it succeeds in moving the basic reproduction number away from the transmission optimum via reinfection. This can be achieved either by choice of the screening interval or by rescreening those individuals who tested positive in a first screening test. There is an optimal time interval for retesting that minimises the basic reproduction number. The precise numerical value depends on partnership durations and transmission probabilities.

\section{P1-S5.42 PREVALENCE OF TRANSITIONAL AND EMBEDDED CONCURRENCY WITHIN A PROSPECTIVE COHORT OF URBAN ADOLESCENT FEMALES}

doi:10.1136/sextrans-2011-050108.220

${ }^{1} \mathrm{P}$ Matson, ${ }^{1} \mathrm{~S}$ E Chung, ${ }^{2} \mathrm{~J} D$ Fortenberry, ${ }^{1} \mathrm{~J}$ Ellen. ${ }^{1} \mathrm{~J}$ ohns Hopkins School of Medicine, Baltimore, USA; ${ }^{2}$ Indiana University-Purdue University Indianapolis, Indianapolis, USA

Background Studies have found that concurrent sexual partnerships, as opposed to cumulative number of sex partners or serially monogamous partnerships play a pivotal role in rates of STI transmission. Different patterns of concurrency have different consequences to STI transmission as these patterns result in diverse network structures from within which to disseminate disease. Our objective was to determine the prevalence and types of concurrent partnerships within a prospective cohort of urban adolescent females.

Methods A cohort of adolescent females $(\mathrm{N}=63)$, aged $16-19$ at baseline, were recruited from health clinics and community venues in Baltimore, $\mathrm{MD}$ and completed daily diaries about each current sex partner on a Palm Smartphone continuously for up to 18 months. As data collection is ongoing, relationships that were at least 8 weeks long were selected for this analysis. Partner names were confirmed by participants at regular intervals to ensure the same partner was followed over time. Sex partners were considered concurrent if they were named by the participant in the same week. Concurrent partners were categorised as either embedded or transitional relative to each relationship. A side partner was categorised as embedded if the week(s) that partner was named were completely contained within the weeks of the relationship. A side partner was categorised as transitional if weeks that the partner was named either preceded or persisted beyond the relationship or if the partner was only named in a single week within the first or last 4 weeks of the relationship.

Results Fifty-five participants had a relationship of at least 8 weeks duration, of these 55 relationships $28(51 \%)$ had a concurrent partner within the relationship, with a mean (SD) of 2.7 (2.6) concurrent partners. Of the 28 relationships that contained concurrency, transitional concurrency was most prevalent (43\%), followed by both transitional and embedded (39\%), and embedded only (18\%). Among relationships with concurrency, 25\% had a gap of $>4$ weeks within the relationship, as a result partners initially classified as transitional subsequently became embedded. There was no difference in relationship duration for those with and without concurrency.

Conclusions Transitional concurrency may reflect adolescents' intentions of serial monogamy. Future data collection is needed to gain an improved understanding of adolescents' motivations for concurrent sexual partnerships.

\section{Epidemiology poster session 5: Transmission dynamic: Income/race disparities P1-S5.43 DISPARITIES IN SEXUALLY TRANSMITTED DISEASES
ACROSS RACE-INCOME "COUNTIES IN THE USA: A RACE-
SPECIFIC MORBIDITY ANALYSIS"}

doi:10.1136/sextrans-2011-050108.221

K Owusu-Edusei, H Chesson, J Leichliter, C Kent, S Aral. Centers for Disease Control and Prevention, Atlanta, USA

Background We examined the association between race-specific incidence rates for three major bacterial STDs and race-specific household income at the county level for all counties in the 48 contiguous states in the USA.

Methods Race-specific county-level median household incomes were obtained from the 2000 decennial census. We used the overall US median household income (ie, $\$ 41994$, in 2000 dollars) as the cutpoint to categorise counties into six race-income county groups. "Race-income" county groups were defined by black household income and white household income at the county level (see Abstract P1-S5.43 table 1). County-level race-specific morbidity for chlamydia, gonorrhoea and primary and secondary (P\&S) syphilis were obtained from the National Electronic Telecommunications System for Surveillance (NETSS) for 1999-2001. For each of the six county groups, we calculated race-specific STD rates (new cases per 100000 residents) using the total number of cases and population size for all three years. In a supplemental analysis, we used a spatial regression technique to examine the association in more detail, controlling for county-level socio-demographic factors.

Abstract P1-S5.43 Table 1 Average race-specific STD rates (number per 100000 residents), 1999-2001 for six "race-income" county groups

\begin{tabular}{|c|c|c|c|c|c|c|c|}
\hline \multirow{2}{*}{$\begin{array}{l}\text { County } \\
\text { group }\end{array}$} & \multirow{2}{*}{$\begin{array}{l}\text { Description of race-specific } \\
\text { household income in county group }\end{array}$} & \multicolumn{2}{|c|}{ Chlamydia } & \multicolumn{2}{|c|}{ Gonorrhoea } & \multicolumn{2}{|c|}{ P \&S syphilis } \\
\hline & & Black & White & Black & White & Black & White \\
\hline 1 & $\begin{array}{l}\text { Black and white incomes below } \\
\text { national median }\end{array}$ & 695.2 & 88.8 & 597.0 & 22.9 & 10.7 & 0.5 \\
\hline 2 & $\begin{array}{l}\text { Black income below national median, } \\
\text { white income above national median }\end{array}$ & 691.1 & 67.5 & 625.3 & 23.5 & 14.0 & 0.7 \\
\hline 3 & $\begin{array}{l}\text { Black income above national median, } \\
\text { white income below national median }\end{array}$ & 279.3 & 61.3 & 125.4 & 5.6 & 6.2 & 0.1 \\
\hline 4 & $\begin{array}{l}\text { Black and white incomes above } \\
\text { national median }\end{array}$ & 220.6 & 29.2 & 176.1 & 6.3 & 4.2 & 0.3 \\
\hline 5 & $\begin{array}{l}\text { No black households in county; white } \\
\text { income below national median }\end{array}$ & - & 55.3 & - & 3.0 & - & 0.2 \\
\hline 6 & $\begin{array}{l}\text { No black households in county; white } \\
\text { income above national median }\end{array}$ & - & 55.1 & - & 3.8 & - & 0.0 \\
\hline
\end{tabular}

Results STD rates for Blacks in each category were at least 4 times higher than for whites. For chlamydia, county group 1 had the 